\title{
The Roles of the Teachers and Students in the Integrative Language Teaching Approach and Factors That Affect the Use of the Approach in Actual Classroom: Review Article
}

\author{
Amarech Alaye Wondimu Tegegne \\ Wolaita Sodo University
}

\begin{abstract}
With the spread of English as a lingua franca and as the medium for world-wide broadcasting of information and knowledge, in many cases, the pragmatic objectives of language learning emphasize the importance of integrated language skill teaching and flexible instruction. In general, insight on current language curriculum, teaching reading is typically associated to instruction on writing and vocabulary, teaching writing can be easily tied to reading and grammar, and speaking skills readily lend the learners to teaching listening, pronunciation, and cross-cultural pragmatics. In connection to this, Shen, (2003) confirms that the implementation of language in communication, should closely integrates linguistic competence with communicative skills and communicative culture in the process of language skill teaching so that the learners' linguistic competence and their communicative skills can be improved simultaneously. These had to be interaction-centered and as authentic as possible to enable students to use the language skills for purposeful and effective communication. To achieve the envisioned objectives of the integrative language teaching approach, both students are expected to play different roles. Furthermore, the effective practices of the integrative language skills teaching in the classroom may be challenged by different factors. Hence, the factors should be identified and addressed to effectively use the integrative approach to language skills teaching. In connection to this, the main purposes of this review article was to describe the roles of the teachers and students in integrative language teaching approach and to present the factors that affect the practice of this approach. To achieve this objectives various, books, book chapters, guidelines, research findings and documents were critically reviewed and analyzed. Accordingly, this review article describes the roles of the teachers and students in integrative language skill teaching approach. In addition, it presents the major factors that affect the practices of the integrative language skills teaching approach.
\end{abstract}

Keywords: Teachers, Students , Integrative, Language, Teaching Approach, Factors, Use, Actual Classroom DOI: $10.7176 /$ JLLL/80-01

Publication date:June $30^{\text {th }} 2021$

\section{Introduction to Integrative Language Teaching Approach}

An integrative approach is the approach of teaching language skills simultaneously. This means the four macro skills (reading, writing, speaking, and listening) are taught concurrently. Richards and Rogers (2001) define it as "integrated language skills teaching approach is "the teaching of the language skills of reading, writing, listening, and speaking in conjunction with each other as when a lesson involves activities that relate listening and speaking to reading and writing." According to Afnan, (2014), integrating language teaching approach is vital technique for effective language learning. This technique refers to including two or more than two language skills, in a lesson/ task. Richards and Schmidt (2010) as cited in Afnan 2014 also define this approach as relating reading, writing, speaking, and listening together in activity that can be taught via a holistic method. Integrating language skills teaching can be described as a whole-language approach or a multi-skill syllabus. This is because the approach teaches all the language skills together.

Integrated language skills teaching approach is a whole language approach. That is, if a lesson deals with reading skills, then, it will also deal with listening, speaking, and writing skills. It emphasizes on communication purpose in addition to academic success (Hungyo and Kijai 2009 as cited in Elena and Lorena 2011). The four English language skills can be taught integratively in the actual classroom situation via integrative approach. For example, by practicing conversational skills the learner can focus not only on speaking but also listening, in order to reply and ask appropriate follow-up questions. All language skills are considered and to be essential components to develop the communicative competence of students, the skills should be taught together via interactive language teaching approach. Thus, the approach advocates integration of all language skills in actual classroom situation (Crystal, 2003). In other words, integrated language skill teaching approach is the natural way of learning a language. In real life communication, language skills are rarely used in isolation; it is a rare situation where one of the four skills occurs alone. For example, to engage in a conversation, one needs to be able to speak and comprehend at the same time (Jing, 2006).

In terms of integration skill Oxford (2001) introduces the concept of tapestry, it is woven from different strands including the teacher, learner, setting, and relevant languages besides four skills. She believed that absence of such threads may lead to a discrete, segregated skills-like in a real tapestry parallel threads not 
touching, supporting, or interacting with each other. Additionally she argue that in integrative language skill teaching includes associated or related skills such as knowledge of vocabulary, spelling, pronunciation, syntax, meaning, and usage. According to her, this forms an integrated language teaching approach.

In effective lessons language teachers must be integrate language skills simultaneously in order to make language learning as realistic as possible which is a requisite in communication. Often one skill will reinforce another; we learn to speak, for example, in part by modeling what we hear, and we learn to write by examining what we can read (Brown, 2001). For instance, teaching reading can be easily tied to instruction on writing and vocabulary, and oral skills readily lend themselves to teaching pronunciation, listening, and cross-cultural pragmatics (Hinkel, 2001; Lazaraton, 2001; McCarthy and O`Keeffe, 2004). Furthermore, other scholars confirm that language learning tasks should be designed in an integrative manner (McDonough and Shaw, 2003). This helps students to be involved in language tasks that integrate different language skills and advance their skills (Hulstijn and Laufer, 2001).

Moreover, educators(such as Fotos,2002; Ellis, 2003; Snow, 2005) argue that integrative language skill instruction can increase learners opportunities for language learning and purposeful communication, interaction, real-life language use and diverse types of contextualized discourse and linguistic features, all of which have the goal of developing students language proficiency and skills. When the four primary skills of language: listening, reading, speaking and writing are interwoven during instruction, it helps us emulate real-life language use and it also paves the way for optimal language learning to take place (Oxford, 2001). In addition to this purposes, integration of four skills can develop communicative competence, because the real life demands from the learners not only immersion into the knowledge of language, but also into the knowledge about how to use the language appropriately in communicative situations (Jing,2006).

From the above discussion, it can understand that integrated language teaching skill approach is the usual way of learning a language and allows teachers to track students' progress in multiple skills at the same time. Integration of language skills will expose learners to actual language use and encourage interaction (Oxford, 2001). Furthermore, there are several advantages of using integrative approach to teach language skills.

\section{Advantages and Disadvantages of Integrative language skill teaching Approach \\ 2.1. Advantages of Integrative Language Skill Teaching Approach}

For a few years there have been many opinions reinforcing the idea of language as a whole and proposing that the integration of the four skills is the key for creating a classroom environment as authentic as possible in order to teach English just like a real life communicative situation (Elena and Lorena, 2011).

Despite our history of treating the four skills in separate segments of a curriculum, there is a recent trend toward skill integration which clarifies the advantages of this approach in EFL classrooms (Brown 2001). There are numerous benefits of using an integrated-skills approach in language teaching. First, integrating language skills provides more purposeful and meaningful learning at all levels. Besides, it facilitates to coherent teaching and communication. It also brings variety into the classroom, when the teachers develop classroom instructions by integrating language skills cooperatively (Murphy, 1991). If the students use integrative approach, they may learn to operate the language and they can share the acquired knowledge to the others simply (River, 1981).

Implementing of all language skills promotes language learning and affects the L2 knowledge of learners positively (Peregoy and Boyle 1997). When the language skills are integrated in language teaching, language learning comes closer to the way we do in real life (Almarza Sanchez, 2000). This means language integration is essential to communicate in effective and successful way in real life, and integrative the skills can give ample benefits to teaching English, it is advisable method in actual class room situation despite its higher demanding for teachers (Jing, 2006).

Integrating the four skills emphasizes the focus on realistic language and can, therefore, develops learners communicative competence in English (Jing, 2006). Nunan(1989) believes that integration of language skills is very important to every day communication, language teaching_ learning process and task outcomes. (Schurr et al, 1995) established that the language use is holistic in the real world, this demands from the Language teachers to provide learners with an environment where they can immerse in reading, writing, speaking and listening.

According to Hungyo and Kijai (2009) as cited in Elena and Lorena (2011) stated that one of the advantages of using this approach is that teachers can prepare the lesson plan around a theme or a topic based on the interest of learners and also on topics that are relevant to them which contributes to make lessons more dynamic and attractive for learners, who participate in different kinds of activities and discussion. But according to Oxford (2001) as cited in Elena and Lorena (2011) one of the most advantages of using the integrated language teaching approach is that it exposes English language learners to authentic language and challenges them to interact naturally in the language. She also comments that exposing students to communicative situation helps and empower to them of the richness and complexity of the English language.

Mohan, (1986) states that each language skill is not used separately in day to day and real life communication, so skill integration is crucial point in language learning. The effective classrooms must be apply 
all language skills just like the real world communication; this refers to using cooperative learning activities as one of the best ways to realize this (Arslan, 2008). He expresses that a language teacher uses integrated-skill in classroom, it provides to the learners with opportunities to interact naturally in the language without any difficulty. This helps to them advance their communication, increase their interest towards the language as well as a means to pass the examination. Generally some scholars thought and research findings show that skill integration has many advantages. For instance, Strang, 1972 believes that skill integration helps the learners to become responsible over their language skills. It creates a dynamic and exciting classroom environment (Richard-Amato, 1996) and Enables learners to have a more realistic access to authentic language learning (Myers \& Hilliard, 1997). Mitrofanova \& Chemezov, 2011), noted that language integration may increase students language learning motivation and leads to better comprehension of the material by students.

Furthermore, this approach allows teachers to track students' progress in multiple skills at the same time and promotes the learning of real content. It is motivating to students, the application of integrated skill approach into the EFL classroom, where the teacher is using authentic materials, is likely to guarantee success in language learning Oxford (2001). Adeyemi (2010) as cited in Supaporn, (2015) expresses that integrated language teaching approach provides students with more comprehensive learning that is rich and interesting. It makes the classroom atmosphere more enjoyable and thought-provoking.

Moreover, integrative language skill teaching approach may help a teacher to make the lessons active, involving the students in varied activities and interactions, which can create plenty of opportunities for students to participate in class and increase their motivation to learn English. It also helps the students to learn English freely and comfortably way (Oxford, 2001).

\subsection{Disadvantages of Integrative Language Skill Teaching Approach}

Despite the above advantages, the teaching of integrated language skills via integrative approach can also have a number of disadvantages (e.g., McDonough and Shaw 2003; Widdowson, 1978, 1993; 2003). To begin with, a curriculum that concentrates on a single language skill at a time can permit more focused teaching and more intensive learning. Besides, in various regions and cultures where the instruction in discrete language skills is highly valued, both teachers and learners have been known to resist skill integration (Richards and Rodgers, 2001). In such settings, integrated instruction may not be well suited to the developing countries like Ethiopia because lack of sufficient materials. Regarding to this, the current study was investigated the problems that EFL teachers face while teaching language skills integratively.

In addition, complex integrated instruction with more than two language skills addressed in leads greater demands on both the teacher and the learner. The teacher expected to be well -trained and skillful as much as possible. At the same time, teachers can be expected to devote more time and effort to preparing materials appropriate for integrated instruction. In many regions around the world especially poor countries where teachers are required to teach very large classes, the teaching of integrated skills may not be a very practical option (Hinkel, 2001).

Another disadvantage of integrated instruction is, learners have unequally developed proficiencies across the four macro-skills (Hinkel, 2002; 2003; Stern, 1983). For example, second language learners who live in English-speaking countries may have stronger skills in listening and speaking than in reading and writing. On the contrary, English as a foreign language learners are likely to be better readers and writers than listeners and speakers. For this reason, the teaching of integrated language skills can become complicated, when instructional materials and practice have to account for a considerable variance in learners' abilities (Richards, 2005). For this study, an attempt was made to explore teachers' responses on the advantages and disadvantages of the integrative language teaching approach. The advantages of using the integrative approach to teach language skills can be optimized and its disadvantages can be minimized if both teachers and students effectively discharge their assigned roles and responsibilities. Next, the roles of the teachers and students in integrative language skill teaching approach is described.

\section{The Role of the Teachers and Students in Integrative Language Skill Teaching Approach}

In language skill Integrative teaching approach, both teachers and students are participants in the classroom activities, they should have their own role. Below are the key roles of teachers and students in integrative language teaching approach.

\subsection{Teachers Role in Integrative Language Skill Teaching Approach}

In traditional language teaching, teachers play more important roles than student in education, especially before in the 1960s and 1970s. Teacher is considered as knowledge-giver" (Cortazzi and Jin 1996), who dominates the class from the beginning to the end. According to Richards and Rodgers (1986), the teacher acts as the model of language, the lesson planner, the controller of learner practice and the evaluator of learner's performance, the organizers in the teaching program in terms of knowledge of grammar, the planners of the course, preparing the 
materials and deciding what and how learners ought to learn( Shanghais,2012). But, integrative approach suggests that teachers allow students to explore and generate new knowledge during the teaching learning process. This can be accomplished through an interactive learning environment. It is characterized by different questioning techniques, authentic problem solving tasks, and learners' verbal and written sharing of thoughts. When learners have successful experiences in expressing themselves, they have not only accomplished the communicative function, but have also gained confidence in using the second language (Wan, 1996).

In this approach a teacher has the responsibilities of organizing varies kinds of activities which are appropriate, effective and relevant to the teaching of language skills and which will best meet the students' needs and expectations. The teacher should give clear instructions as to what to be done because the success of many activities, no matter whether it is a specific role-play or a group discussion, depends on good organization and on the students knowing exactly what they are expected to do. Teacher's role as manager and organizer is considered to be the first and foremost role teacher has to play in the class (Shanghais, 2012).

On the other hand, in integrative language skill teaching approach, teachers are not the only source of language information in these days of global interconnectedness, and the language teachers should understand that students need to develop strategies to respond and adapt to changes rather than approaching the task of language learning in a uniform way (Warschauer and Healey, 1998). They also believe that the teacher should play the role of facilitator rather than being the source of knowledge.

Moreover, language teachers should take the responsibilities to integrate language skills through different mechanisms like organizing the learners in groups, to select appropriate materials that must be much with in this approach, create awareness towards integrative approach and etc.

In this sense, Wright (1991) classifies the term such as manager, resource provider, guide, evaluator, and organizer and introductory into two major roles of teachers in the classroom:

1. "To create the conditions under which learning can take place: the social side of teaching".

2. "To impact, by a variety of means, knowledge to their learners: the task-oriented side of teaching"(Wright p.51).

The more progressive view can find support by many researchers, to name only a few of whom, Debski et al. (1997), Chapelle (2001), and Wang (2004). The roles of the teachers in classroom are as follows.

Generally, in integrative language skill teaching approach teachers must be shift their roles from a dominator to a director and give consent to the students to learn positively. The teacher must believe in the students' performance, respect and motivate them to engage in the classroom activities and create suitable situations. Learners also learn and study actively under the teacher's instructions. Therefore, the teacher should be monitoring, modeling, and motivating, guiding learners' activities. In other words, they can be as manager, organizer, facilitator, counselor in the classroom situation in order to make the lesson effective (Shanghais, 2012).

\subsection{Learners' Role in Integrative Language Skill Teaching Approach}

As a teacher, students also have their own role in integrative language skill learning and engage in negotiating meaning try to make themselves understand even when their knowledge of the target language is defective. They learn to communicate by communicating and take much time to speak. It is through interaction between speakers and listeners or readers and writers that meaning becomes clear. Students work on all four skills from the beginning and they often work in small groups or teams. Therefore, students have chance to speak, exchange their point of view, knowledge and information. Because of the increased responsibility to participate, students may find they gain confidence in using the target language in general. Students are more responsible managers of their own learning (Larsen-Freeman, 1986).

\section{Factors that affect the use of Integrated Language Skills Teaching Approach}

In foreign Language learning context, there are various factors that influence the teaching learning process such as motivation, attitudes, anxiety, learning achievements, aptitudes, intelligence, age, personalities, etc Lehmann, (2006) as cited in Mehamad, (2012). In this regard, many scholars such as Oxford, 2001; Richards, 2001, Edge, 1993; Frazee,1995; also confirm that there are several factors that hinder implementation of integrative language skill teaching. These factors can be categorized into three different groups namely, school factors, learner factors and teacher factors.

\subsection{Teachers' Factors}

We can see this factors in two way; teachers' knowledge about teaching integrative skills and his/ her attitude.

\section{A. Teachers' Knowledge}

Educators, have pointed out that a particular feature of teaching skills is their interactive nature. A teacher's action during a lesson continuously need to take account of changing circumstances. Indeed, a teacher's effectiveness in the classroom is very dependent on how well they can modify and adapt their actions in the light 
of how well the lesson is going. Thus, in effective teaching skills teachers should have enough knowledge (Campbell et al., 2004; Muijs and Reynolds, 2005). Shulman,1987 also believes that teacher knowledge is crucial point in teaching skills in integrative ways. These include:

- knowledge about content(subject matter).

- knowledge about broad principles and strategies of classroom management and organization.

- knowledge about how to prepare lesson plans and implementation

- knowledge about learners interest. attitude etc.

One can infer that from the above point EFL teachers must be active, skillful and in order to tackle different problems and achieve certain goal. Moreover, teachers should be designing integrated activities for their students. In developing learners skills a teacher therefore is as much about developing and extending her/ his knowledge about the decision you may take in a particular situation as it is about the successful execution of the observable action(Chris, 2007).

\section{B. Teachers' Attitude}

Teachers' and learners' attitudes are very important to implement different techniques and methods of teaching language skills (Rogers, 2003). Attitude is a settled behavior or manner of acting reflecting individuals' feelings or opinions. This definition suggests that individuals' beliefs are crucial in determining their behaviors (Mohammed, 2006). Attitudes are defined as the interplay of feelings, beliefs and thoughts about actions (Rusch \& Perry, 1999) as cited Rahimi \& Naderi (2013). As discussed before integrating the four skills can help the development of students 'communicative competence but can be demanding of the teacher. We need to have a good understanding of discourse, and to be able to use textbooks flexibly. Therefore, the teacher perception is very essential towards implementing of this approach and readiness of challenging these problems. We can conclude that teachers' attitudes and beliefs remain the single strongest guiding influence on instruction (Gorsuch 2000 as cited in Rahimi and Naderi (2013), these negative attitudes can be the source of difficulties teachers face in implementing integrative language teaching approach.

\subsection{Learners' Factor}

Attitudes can be viewed as a tendency to respond positively or negatively towards a certain thing, idea, person, situation, etc.) Gardener (1985) as cited Hashem, A and D Salem, S(2015 in defines attitude as an evaluative reaction to some activities, situations, inferred on the basis of the individual's beliefs or opinions about the activities. As for education, Brown (2000) as cited in Hashem and Salem (2015) notes that teachers should recognize that all students possess positive and negative attitudes in varying degrees and adds that the negative attitudes can be changed by thoughtful instructional methods, such as using materials and activities that help students achieve an understanding and appreciation of foreign culture, a fact that might be reflected in the process of learning in the foreign language.

The matter of learner's attitude is acknowledged as one of the most important factors that impact on learning language (Fakeye, 2010) as cited in Mohamad (2012). Thus, developing students' attitudes towards learning is considered to be one of the most important issues that should be taken into account factors affecting language teaching-learning process. Hashem and Salem, (2015) also confirmed that understanding learners' attitude is unquestionable issue to proceed effective language classes. Their views of communicative aspects are necessary in actual instructional practices should guide the pedagogical decisions associated with their learning (Tigist, 2002). An essential feature of the teaching skills involved in establishing a positive classroom climate is best to foster pupils' motivation towards learning (Chris 2007 Edge, 1987; Oxford, 2001).

According to Jones 1984 as cited Abebayehu (2011) learning is related to attitudes; what is learned may depend on the attitude of the learner. Students' attitude toward the teacher, the school and various subjects are primarily important in the teaching learning process. He also cited in Chamber (1999) claimed that learning occurs more easily, when the learner has a positive attitude towards the language and learning. Hence, attitudes have their own effect on the process of learning. This means, it either facilitates or hinders learning. Students' lack of motivation in class participation can be taken as the symptom of their antagonistic attitude to the given context. Prodromou (1992) as cited in Abebayehu,(2008) also a successful learner is the one who possess positive attitudes towards the target language.

Moreover, Baker (1988) as cited in Abebayehu,(2008) believed that attitudes towards a particular language learning might be either positive or negative. Some learners may have negative attitude towards the foreign language and want to learn it in order to prevail over people in the community. Some students might generate neutral feelings. Attitudes towards language are likely to have been developed by students' experiences. We can infer that, learners, engagement of classroom activities that done to be improve language skills are very important element to effective classes (Chris, 2007; Edge, 1987; Oxford, 2001). Learners positive attitude towards learning strengthens their motivation to perform activities successfully and it becomes a means of effectiveness (Baker, 1988) as cited in Abebayehu(2008). 


\subsection{School Factors}

When we say school factors such as sufficient materials that used to proceed effective language skill teaching via integrative approach. But most government schools in Ethiopian context may not adequate materials (instruments) and resources, such as student text books, teacher guides, language lab classes, chairs, tables and etc( Cruickshan, Bainer and Metcalf, 1995; Edge, 1987; Richards, 2001). Moreover, most EFL teachers in the world reject teaching in large groups due to the large mixture of students, heterogeneous ages and abilities, learning and individual attention difficulties. Teachers think that they can get better pedagogic results in small number of learners. Thus number of students in a single class hinder normal teaching learning process ( Yolima 2005). In connection to this, the present study was conducted which problems are barrier of language skill teaching in integrative way and how language teachers tackle these problems and proceed successful language skill teaching/learning.

\section{References}

Afnan,M.(2014), Kumaravadivelu's Framework as a Basis for Improving English Language Teaching in Saudi Arabia: Opportunities and Challenges: Vol. 7, No. 4; Canadian Center of Science and Education.

Almarza. S, M. A.(2000). An Approch to Integration of Skills in English Teaching; Didactica (Lengua y Literatura) : pp.21-44

Arslan, A.(2008). Implementing a Holistic Teaching in Modern ELT Classes: Using Technology and Integrating Four Skills :Naval Training Center.

Brown, H.D. (2001). Teaching by Principles: An Interactive Approach to Language. Pedagogy 2nd Ed., Newyork: Pearson Education.

Crystal, D. (2003). English as a global language. 2nd ed: Cambridge University Press.

Ellis, R. (2003). Task-based language learning and teaching. Oxford: OUP learner autonomy, cultural awareness. Australia: European Centre for Modern Languages.

Fotos, S. (2002). Structure-based interactive tasks for the EFL grammar learner. In English.

Hinkel, E. (2001). Building awareness and practical skills for cross-cultural communication in ESL/EFL. In M. Celce-Murcia (Ed.), Teaching English as a second or foreign language (3rd ed., pp. 443-458). Boston: Heinle \& Heinle.

Hinkel, E. (2002). Second language writers' text. Mahwah, NJ: Lawrence Erlbaum.

Hinkel, E. (2003). Simplicity without elegance: Features of sentences in L2 and L1 academic texts. TESOL Quarterly, 37, 275-301.

Hulstijn, J.H., \& Laufer, B. (2001). Some empirical evidence for the involvement load hypothesis in vocabulary acquisition. Language Learning, 51(3), 539 - 558.

Jing, W. (2006). Integrating Skills for Teaching EFL -Activity Design for the Communicative Classroom, Sino-US English Teaching. V. 3, No.12 (Serial No.36).

Lazaraton, A. (2001). Teaching oral skills. In M. Celce-Murcia, Teaching English as a second or foreign language (3rd ed., pp. 103-115). Boston: Heinle \& Heinle.

McCarthy, M., \& O`Keeffe, A. (2004).Research in the teaching of speaking. Annual Review

McDonough, J. \& Show, C. (2003). Materials and methods in ELT: A teachers guide. of Applied Linguistics, 24. $26-43$.

Murphy, J. M (1991). Oral Communication in Tesol: Integrating Speaking, Listening And Pronunciation; Tesol Quarterly; 25 (1); Oxford University Press.

Myers, J. W., \& Hilliard, R. D. (1997). Holistic language learning at the middle level: Our last, best chance. Childhood Education, 73, 286-289.

Nunan, D. (2005). Important tasks of English education: Asian EFL Journal, 7(3), 5-8.

Oxford, R. (2001). Integrated skills in the ESL/EFL classroom. ERIC digest ERIC Clearinghouse on Languages and Linguistics.

Peregoy, S., and O. Boyle. (1997). Reading, Writing and Learning in ESL 2nd Ed. Newyork: Longman.

Richard-Amato, P. A. (1996). Making It Happen. New York: Addison-Wesley.

Richards, J.C. and T.S. Rogers.( 2001). Approaches and Methods in Language Teaching (2nd Edition). Cambridge: Cambridge University Press.

Richard s, J. C., \& Schmidt, R. (2010). Longman dictionary of language teaching and applied linguistics. Harlow, UK: Longman.

Rivers, W.M. (1981). Teaching Foreign-Language Skills. Chicago, The University of Chicag Press.

Strang, R. (1972). Developing oral expression. In H. D. Funk, \& D. Triplett (Eds.), Language Arts in the Elementary School: Readings (pp. 287-293). Philadelphia: J. P. Lippincott Company. 